\title{
Hysterectomy: clinical profile, indications and postoperative complications
}

\author{
Sucheta $\mathrm{KL}^{1}$, Mallikarjuna Manangi ${ }^{2}$, Madhu $\mathrm{KP}^{3}$, Arun $\mathrm{BJ}^{4}$, Niranjan Nagaraj ${ }^{5 *}$ \\ ${ }^{1}$ Junior Specialist, ESI Dispensary Bangalore, India \\ ${ }^{2}$ Department of Surgery, ${ }^{3}$ Department of Anaesthesia, Victoria Hospital, Bangalore Medical College and Research \\ Institute, Bangalore, India \\ ${ }^{4}$ Department of Respiratory Medicine, Kempegowda Institute of Medical Sciences, Bangalore, India \\ ${ }^{5}$ Department of Paediatrics, S.P. Medical College, Bikaner, Rajasthan, India
}

Received: 03 June 2016

Accepted: 06 June 2016

\section{*Correspondence:}

Dr. Niranjan Nagaraj,

E-mail: getniranjan806@yahoo.com

Copyright: () the author(s), publisher and licensee Medip Academy. This is an open-access article distributed under the terms of the Creative Commons Attribution Non-Commercial License, which permits unrestricted non-commercial use, distribution, and reproduction in any medium, provided the original work is properly cited.

\begin{abstract}
Background: Hysterectomy is today a relatively safe routine operation performed commonly worldwide. This study aims to know the clinical profile, indications and post-operative complications of patient undergoing hysterectomy. Methods: This is the prospective study of 200 cases of hysterectomy done for benign conditions of uterus. The study period was from July 2012 to December 2014. Women who were tentatively going to undergo hysterectomy in the future were chosen irrespective of their age, parity or clinical presentation. A detail history of their complaints and a thorough physical and gynecological examination was done and recorded on performa.

Results: Women in the study group were between 20-70 years. 50\% belonged to 41-50 years of age. Hysterectomy was predominantly performed in para two and para three cases. Commonest presenting symptom was abnormal menstrual flow (62\%). Commonest indication for hysterectomy was dysfunctional uterine bleeding (DUB) (30\%), fibroid $(23 \%)$ and prolapse $(20 \%)$. Abdominal hysterectomy $(63 \%)$ was performed more commonly than vaginal hysterectomy $(37 \%)$. Complications are more common in abdominal hysterectomy than vaginal hysterectomy.

Conclusions: Women aged between 41-50 years with multiparous status were commonly affected. Abnormal menstrual flow was the commonest presenting complaint. Commonest indications for hysterectomy were dysfunctional uterine bleeding. Abdominal hysterectomies were commonly done than vaginal hysterectomy.
\end{abstract}

Keywords: Hysterectomy, Bangalore, Haemorrahge, Clinical profile

\section{INTRODUCTION}

Hysterectomy is today a relatively safe routine operation performed commonly worldwide. Today approximately $6,00,000$ hysterectomies are performed each year in United States making it second most common operation after caesarean section. ${ }^{1}$ Only 150 years later, hysterectomy was the most common operation performed in United State, and elsewhere, accounting for some 75,000 operation in 1975 in United States itself. ${ }^{2}$
This study of 200 cases of hysterectomies for benign condition of uterus has been taken to correlate the clinical profile with histopathological examination of uterus. It is in this field of non-malignant hysterectomy the indications are often over used resulting in many unnecessary operations. Hence this study will bring about the facts and figures about the clinical indication and final histopathological diagnosis and throw some conclusion on justification of hysterectomy. 


\section{METHODS}

This is the prospective study of 200 cases of hysterectomy done for benign conditions of uterus. The study period was from July 2012 to December 2014 During this study period, over 1000 hysterectomies were done and among these 200 cases were selected randomly. The cases were collected from among those attending the gynaecological outpatient department of Vanivilas Hospital and Bowring and Lady Curzon Hospital, Bangalore, India. Women who were tentatively going to undergo hysterectomy in the future were chosen irrespective of their age, parity or clinical presentation. Out of these the 200 women who underwent hysterectomy either abdominal or through the vaginal route were selected for the study. A detailed history of their complaints and a thorough physical and gynaecological examination was done on them, as per the proforma. A provisional diagnosis was made. Then these patients were investigated thoroughly, few of them underwent D.D and C and cervical biopsy and few of them underwent pap smear. Routine laboratory examination were done like $\mathrm{Hb} \% \mathrm{BT}, \mathrm{CT}, \mathrm{TC}, \mathrm{DC}, \mathrm{ESR}$, blood group and RH typing. Following hysterectomy these patients were followed up in the immediate postoperative period and till six weeks after hysterectomy. The specimen was sent for histopathology examination to the pathology department of Vanivilas Hospital and Bowring and Lady Curzon Hospital, Bangalore, India. All the collected data was tabulated and statistically analyzed by using SPSS software.

\section{RESULTS}

200 men who had undergone hysterectomy for benign conditions of the uterus were studied at Vanivilas Hospital and Bowring and Lady Curzon Hospital Bangalore, India between July 2012 to December 2014. Women in the study group were between 20-70 years. $50 \%$ belonged to $41-50$ years of age.

Table 1: Indications for hysterectomy.

\begin{tabular}{|lll|}
\hline Indication & No. of patients & Percentage \\
\hline DUB & 66 & $33 \%$ \\
\hline Fibroid & 46 & $23 \%$ \\
\hline Prolapse & 40 & $20 \%$ \\
\hline Adinomyasis & $\mathrm{S}$ & $4 \%$ \\
\hline PID & 12 & $6 \%$ \\
\hline Chronic cervicitis & 22 & $11 \%$ \\
\hline $\begin{array}{l}\text { Post-menopausal } \\
\text { bleeding }\end{array}$ & 6 & $3 \%$ \\
\hline
\end{tabular}

Hysterectomy was predominantly performed in para two and para three cases. Commonest presenting symptom was abnormal menstrual flow (62\%). Commonest indication for hysterectomy was DUB (30\%), fibroid $(23 \%)$ and prolapse $(20 \%)$. Abdominal hysterectomy $(63 \%)$ was performed more commonly than vaginal hysterectomy (37\%). Complications are more common in abdominal hysterectomy than vaginal hysterectomy. Febrile morbidity, hemorrhage, wound infection and urinary tract infection were commonly encountered complications after hysterectomy. No mortality was seen in 200 cases studied.

Table 2: Post-operative complications in hysterectomy cases.

\begin{tabular}{|lll|}
\hline Complications & $\begin{array}{l}\text { Abdominal } \\
\text { hysterectomy }\end{array}$ & $\begin{array}{l}\text { Vaginal } \\
\text { hysterectomy }\end{array}$ \\
\hline Febrile morbidity & $20(15.87 \%)$ & $9(12 \%)$ \\
\hline Hemorrhage & $12(9.5 \%)$ & $6(8.1 \%)$ \\
\hline $\begin{array}{l}\text { Abdominal wound } \\
\text { infection }\end{array}$ & $13(10.3 \%)$ & - \\
\hline Urinary tract infection & $10(7.9 \%)$ & $4(6 \%)$ \\
\hline Wound dehiscence & $2(1.58 \%)$ & - \\
\hline Vault abscess & 1 & $2(2.6 \%)$ \\
\hline Rectal injury & - & $1(0.7 \%)$ \\
\hline Lung infection & $3(2.3 \%)$ & - \\
\hline Mortality & $0(0 \%)$ & $0(0 \%)$ \\
\hline
\end{tabular}

Table 3: The type of hysterectomy is tabulated as follows.

\begin{tabular}{|ll|l|}
\hline Surgery & $\begin{array}{l}\text { No. of } \\
\text { cases }\end{array}$ & Percentage \\
\hline A. Abdominal hysterectomy & 126 & $63 \%$ \\
\hline $\begin{array}{l}\text { Total abdominal hysterectomy } \\
\text { only (TAH) }\end{array}$ & 48 & $24 \% *$ \\
\hline $\begin{array}{l}\text { TAH+ bilateral } \\
\text { salpingoopharectomy }\end{array}$ & 30 & $15 \%$ \\
\hline $\begin{array}{l}\text { TAH-f- right } \\
\text { salpingoopharectomy }\end{array}$ & 22 & $11 \%$ \\
\hline $\begin{array}{l}\text { TAH+ LL } \\
\text { salpingoopharectomy }\end{array}$ & 20 & $10 \%$ \\
\hline Subtotal hysterectomy & 6 & $3 \%$ \\
\hline B. Vaginal hysterectomy & 74 & $37 \%$ \\
\hline
\end{tabular}

\section{DISCUSSION}

In this study on 200 hysterectomy cases a few observations were read regarding the anthropometric data, clinical presentation. Type of operation, postoperative complication and histopathological study observations are described below.

The patients were divided into six groups depending on their age. The commonest age group was between 41-50 years and similar reports were also given by Millet et al, Watts et al reported that $45.2 \%$ of hysterectomies were done between 41-50years. ${ }^{3,4}$ Amrika et al found that $37 \%$ were between 41-50 years of age. ${ }^{2}$ Watts et al reported $23.7 \%$ nulliparous and $75.3 \%$ were parous women. ${ }^{4}$

Amirika et al similarly reported much higher incidence in parous women. In this series only $5 \%$ of women were 
nulliparous. ${ }^{2}$ Dickers et al in reported $90.3 \%$ parous woman and $9.7 \%$ were nulliparous. ${ }^{5}$ So we can say that parity has got a definite role to play. Although nulliparous were not altogether immune to lesions requiring hysterectomy. Their number is for less than that of parous woman. In this study we found that 174 cases were Hindus, 20 cases were Muslims and 6 were Christians.

Patient presented with various symptom. The main presenting complaint was abnormal menstrual flow in $62 \%$ of cases, white discharge per vagina $32 \%$ of cases, pain abdomen $25 \%$, backache $22 \%$ of cases, prolapse $29 \%$ of cases and urinary symptoms $6 \%$, abdominal mass $4 \%$, post-menopausal bleeding $3 \%$, pot coital bleeding $5 \%$, dyspareunia $2 \%$, and other associated symptoms like loss of weight 1 , fever $1.5 \%$ were also observed. It was observed that abnormal menstrual flow was the single most complaint comprising of $62 \%$ of cases. Similarly Emil F Cava (35.7\%) and Grant et al in (57.7\%) reported that abnormal menstrual flow was the most common complaint. $^{6,7}$ Next common complaint was white discharge per vagina in $32 \%$ of cases. Miller et al reported $3.6 \%$ and Watts et al reported $0.9 \% .^{3,4}$ This difference is explained due to the powers of observation and fastidious of individual woman who are overanxious may tend to exaggerate the symptom of discharge. Indian woman tent to have poor hygiene, so associated white discharge was found common. Abdominal pain was observed in $25 \%$ of cases. Miller et al reported $17.4 \%$ and Watts et al reported $17.2 \%$ which is almost similar. We observed prolapse in $29 \%$ of cases. Miller et al reported $4.4 \%$, Watts et al found in $12.5 \%$, Emil $\mathrm{F}$ Lave found it $37.9 \%{ }^{6}$ Backache was observed in $22 \%$ of cases as compared to $5 \%$ in Miller et al study and $3 \%$ by Emil Cava. Mass abdomen was observed in $4 \%$ of cases as compared to $2.8 \%$ in Miller et al study. Post-menopausal bleeding was seen in $4 \%$ of cases as compared to $1.2 \%$ in watts et al series. Dyspareunia was observed in $2 \%$ of cases as compared to $3 \%$ in Emil F Cava study. ${ }^{6}$

DUB is the most common indication for hysterectomy constituting about $33 \%$. Similar percentages were quoted by Copen hover $38.9 \%$, Dickers et al quoted $45.3 \% .^{8.5}$ But Ackens et al quoted a very low percentage of $0.4 \%$ in. ${ }^{9}$ Fibroid uterus was the next commonest indication found in $23 \%$ of cases. Dickers et al quoted $47.4 \%$, Miller et al quoted $31.7 \%$ and Ackens et al quoted $74.8 \%$ cases. ${ }^{9}$ Prolapse of the uterus constituted $20 \%$ cases in this study. Prolapse constitute one of the major indications for surgery and according to cope hover it constituted about $41.3 \%$ and according to Amirika it is $3.46 \%$. $^{2}$ Post-menopausal bleeding constituted about $3 \%$ of cases. Copenhover et al reported $1.8 \%$ of cases. Acken et al quoted $0.9 \%$ Adenomyosis was found in $4 \%$ of cases. Acken et al observed in $2.8 \%$, White et al observed in $8.5 \%$, Amirika et al in $12.4 \%$ and Dickers et al $9.8 \%{ }^{1,10}$ So dysfunctional uterine bleeding and Leiomyoma found to be the main indications for hysterectomy and similar reports were observed in other series also. Most of the patients who underwent surgery were given spinal anesthesia whether it is abdominal or vaginal hysterectomy. Only 4 cases of abdominal hysterectomy patients were given general anesthesia due to concomitant systemic disease. Two of the patient had hypertension. In another two cases general anesthesia was given because of failure of spinal anesthesia. 126 cases underwent abdominal hysterectomy in comparison to the 74 patients who underwent vaginal hysterectomy. From the above table abdominal hysterectomy constitutes $63 \%$ of the cases. Out of this $24 \%$ of patient had total abdominal hysterectomy $15 \%$ of patient had associated bilateral salpingo-ophorectomy, $11 \%$ had associated right salpingo-oopherectomy and $10 \%$ had associated left salpingo oophorectomy. $3 \%$ of patient had subtotal hysterectomy subtotal hysterectomy was done because of adhesion and difficult tubo-ovarian mass. Vaginal hysterectomy was done in $37 \%$ of cases. Pelvic floor repair was performed in all cases of pelvic relaxation. So, in our study abdominal hysterectomy was performed more commonly than vaginal hysterectomy in benign condition of uterus. Similar results were given by following authors. Watts et al reported $75 \%$ abdominal hysterectomy and $25 \%$ underwent vaginal hysterectomy. ${ }^{4}$ Emil et al reported $59.6 \%$ abdominal and $40.4 \%$ of cases vaginal hysterectomy. ${ }^{6}$ Dickers et al reported $30.6 \%$ vaginal hysterectomy compared to $69.4 \%$ abdominal hysterectomy. ${ }^{5}$ So, in many of the studies abdominal hysterectomy was done more commonly than vaginal hysterectomy.

Complications encountered in our series are as follows. In abdominal hysterectomy the following complications are noted:

- $\quad$ Febrile morbidity was observed in 20 cases (20.1\%). Patient was said to be suffering from febrile morbidity if oral temperature was $100.4^{\circ} \mathrm{F}$ or more on any two post-operative days excluding first 24 hours. It was observed in $15.8 \%$ of cases constituting the commonest complication noted.

- Post-operative wound infection occurred in 13 cases comprising $10.3 \%$ of cases.

- Hemorrhage: Any patient who required blood transfusion in intra operative or post-operative period is included in this category. 12 patients out of 126 cases required one or more pints of blood either intra operatively or post operatively. That means $9.5 \%$ of cases required one or more pints of blood either intra operatively or post operatively.

- UTI: Urinary tract infection occurred in 10 cases out of 126 cases comprising $7.9 \%$ of cases. Most of these patients had indwelling Foleys catheter which may be cause for this infection.

- Wound dehiscence was observed in two cases which needed resuturing of the wound $(1.5 \%)$.

- Miscellaneous: Pelvic hematoma was seen in one case, post-operative lung infection in three cases, and one patient had thrombophlebitis at the site of IV infusion. 
In vaginal hysterectomy following complication are noted:

- Febrile morbidity occurred in $12 \%$ of cases.

- Hemorrhage occurred in $8.1 \%$ of cases.

- Urinary tract infection in $6 \%$ of cases.

- Rectal injury was seen in one case (\%).

- Vault abscess occurred in 2 cases $(26 \%)$.

In general, complication after vaginal hysterectomy was less as compared to abdominal hysterectomy. We observed that prophylactic antibiotics in beneficial, which the incidence of post-operative complication. This goes well with the studies of Ledger et al, Harralson et al. ${ }^{11,12}$

\section{CONCLUSION}

Hysterectomy will remain a common gynecological operation in both developing and developed countries. The clinical and the pathological correlation are poor, when abdominal pain or dysfunctional uterine bleeding (DUB) was the preoperative clinical diagnosis. Women aged between 41-50 years with multiparous status were commonly affected. Abnormal menstrual flow was the commonest presenting complaint. Commonest indications for hysterectomy were dysfunctional uterine bleeding. Abdominal hysterectomies were commonly done than vaginal hysterectomy. Leiomyoma, adenomyosis and endometrial hyperplasia were commonly found in the histopathological examination of specimen. No mortality was found in this study.
Funding: No funding sources

Conflict of interest: None declared

Ethical approval: The study was approved by the Institutional Ethics Committee

\section{REFERENCES}

1. Acken HS, Zarace JS. Surgery assisted reproductive technology and infertility: diagnosis and management. American J Obst Gynae.1962;84:113.

2. Amirika H, Evans TN. Mode of delivery after obstetric anal sphincter injury and the risk of longterm anal incontinence. Am J Obst Gynae. 1979; $134: 431$.

3. Miller NF. Dysfunctional uterine bleeding. Am J Obst Gyn. 1946;51:804.

4. Watts, Kimbrough. Clinical profile of adenomyosis. J Obst Gyn. 1956;7:483.

5. Dickers RC, Greenspan JR, Strauss L. Clinical study of fibroid uterus. Am J Obst Gyn. 1982;144:841.

6. Emil T, Smith T, Timothy M. Ovarian tumors. Am J Obst Gyn. 1975;122:434.

7. Gray LA. Prevalence of adenomyossis. Clini Obst Gynae. 1982;25(4):869.

8. Copen EH. Clinical outcome of dysfunctional uterine bleeding. Am J Obst Gyn. 1962;84:123.

9. Acken HS, Zarace JS. Hysterectomy and outcome. Am J Obst Gynae. 1962;84:113.

10. White SC, Wortel LJ. Prevalence of cervical carcinoma and surgical management. Am J Obst Gyn. 1971;37:530.

11. Ledger WJ, Gee C, Lows WP. Endometriosis and its oucome. Am J Obst Gyn. 1975;121:1038.

Cite this article as: Sucheta KL, Manangi M, Madhu KP, Arun BJ, Nagaraj N. Hysterectomy: clinical profile, indications and postoperative complications. Int J Reprod Contracept Obstet Gynecol 2016;5:2093-6. 